\title{
Coordinated Development of Paper and Digital Resources in University Library under the Digital Environment
}

\author{
Li Zhangchun ${ }^{1, a}$ \\ ${ }^{1}$ China West Normal University Library, Nanchong City, Sichuan Province, 637000, China
}

Keywords: Digital; University; Library; Paper Resources; Digital Resources; Coordinated Development

\begin{abstract}
In the digital age, the literature structure and service mode of the university library are changing rapidly. The proportion of the digital literature in the library collection system of the universities is constantly increasing. Therefore, how to coordinate the order of the paper and digital resources has positive significance to the library scientific construction. In this paper, based on the author's study and work experience, we first analyzed the necessity of the coordinated development of the paper and digital resources, and then put forward the strategies of the coordinated development of the two resources. It is argued in this paper that the electronic and paper periodical resources should harmonically develop, and the funds should be reasonably allocated. The proper handling of the relationship between paper and electronic periodicals is an important subject for the current periodical interview.
\end{abstract}

\section{Introduction}

The electronic periodical resources have changed the structure of the library collection resources, the library service mode and the readers' behavioral pattern of the use of the library. However, it does not mean that the paper periodicals will be replaced by electronic ones. Paper periodicals are more superior in reading psychology and habits to the electronic periodicals, and their publishing quality and academic level are relatively assured. With the expansion of electronic periodicals, the paper periodicals of traditional resources are unavoidable to be subjected to the impact. The workers in the reading room have proposed to decrease the amount of the periodicals due to the fact that the reading rate of the paper periodicals has decreased year by year. Therefore, how to allocate the paper periodicals and electronic resources has become a difficult problem.

\section{The necessity of coordinated development of paper literature and digital resources}

\subsection{The change of collection concepts of coordinated development of the paper literature and digital resources}

In the case of the continuous increase in book prices and lack of purchase funds, the pursuit of collecting all the necessary books is an impossible task. Some universities purchase large quantities of books and introduce all kinds of newspapers and magazines to increase the library collections, whose amount is massive, and categories are rich. However, their quality is uneven. In the aspect of digital resources construction, there still exist the phenomena of blind comparisons and one-sided pursuit of the purchase of databases and the number of electronic books and periodicals without the consideration of use efficiency, which results in the dislocation of the development of the library itself and its readers' service functions. It is an effective way to expand the amount of library resources by changing the traditional collection concepts, give up doing things in one's own way, and use the resources co-construction, co-knowing and co-sharing to achieve the coordinated development of the paper literature and digital resources.

2.2 The reform of service concepts of coordinated development of the paper literature and digital resources 
The traditional library mainly collects the books and literature which take the paper as their carriers. It provides library-centered services mainly including reading inside the library, books and periodicals lending, literature copy, reference consultation and readers training. However, the digital library is user-centered, brings the services to the market, and carries out the deep processing of the information, whose services include consultation and check replacement, literature delivery, interlibrary lending, CD search, online directory query, online reference consultation, special information services etc. it can provide broader scope and carrier of information resources. The coordinated development of the paper literature and digital resources has led to the reform of service concepts from traditional concepts of literature collection, conservation and supply to more emphasis on the ability of information organization.

\subsection{The layout of resources rationality of coordinated development of the paper literature and digital resources}

The literature construction of the university libraries is based on their own discipline characteristics. In the construction of book collection, professional book collection must be determined by considering the needs of teachers and students. Besides, it needs to consider not only the literature for the systematic learning of professional knowledge of the professional readers, but also the collection of professional treatises which can help them improve their professional interests, and are useful for them to devote themselves to studying the expertise. The coordinated development of the paper literature and digital resources can break the coexistence of the duplication and shortage of the existing collections in the university library, make the layout of the library resources of the university library gradually become reasonable, be helpful to construct the co-sharing system of literature resources in the university library, and increase the social security rate of literature resources.

\subsection{The improvement of literature resources utilization ratio of coordinated development of the paper literature and digital resources}

The rapid development of modern computer technology and network technology makes the traditional library faced with enormous challenges in the information environment, which results in the emergence of the gradual decline in traditional books and periodicals utilization ratio and the failure to make full use of the digital resources. To change the current situation of low utilization rate of paper literature in university library and less amount digital resources, and solve the contradiction between university library's own development and low utilization rate of books and materials, the priority should be given to make full use of computer network technology to enrich and improve the tradition library, constantly update a variety of books and digital resources, improve the various service systems, achieve the coordinated development of the paper literature and digital resources, make the traditional library successfully be transformed to the modern digital library, and effectively improve the utilization rate of literature resources.

\section{The Strategies of Coordinated Development of Paper Literature and Digital Resources}

\subsection{Scientifically formulate the literature resources construction, and take both paper literature and digital resources into account}

The construction of library literature resources is a process of long-term choice and gradual accumulation. The coordinated development of paper literature and digital resources is the premise of the construction of modern library collection resources. The principle of guaranteeing the key disciplines and also taking other disciplines into account should be followed to make the overall planning of paper literature and digital resources construction. The paper printed books of the professional core literature and fundamental literature with high utilization rate should be preserved. For the literature with low utilization and high professional value, the order of electronic literature should be considered, the way of full text delivery should be adopted to meet the needs of individual readers, and the way of purchasing an online search service can be used to save it. The literature 
should be largely purchased, whose electronic version can be obtained by purchasing paper documents or spending a small amount of fee. In regards to the information resources for teaching such as textbook and reference books, the paper literature should be provided, and the E-books can only be considered as the substitution because the digital resources cannot be comparatively read. The statistical analysis should be made on the composition of the literature collection. The statistical data can be used to analyze the satisfaction degree, utilization effect and existing problems of the readers' needs in a certain period, reasonably divide the funds proportion between the paper literature and digital resources, and promote the scientization and rationalization of the collection resources.

\subsection{Guide readers' reading interests and tendencies, and improve the utilization rate of paper literature and digital resources}

The main function of the university library is to provide high quality service for teaching and research. The traditional library considers the stacks and reference room as the resources gathering place, and the provided services are simply borrowing, returning and reading. Modern library, a gathering place for knowledge, should respect the initiative and creativity of the learners, and advocate promoting the potential of learners and researchers in a variety of learning. On the basis of preserving the traditional borrowing and reading services, the readers will be guided by the preparation of the recommended bibliography, guiding bibliography and book exhibition, all the circulations of paper literature, electronic literature and other literatures should be taken into account, and the paper literature open-shelf borrowing and electronic resources online services should be actively popularized. The more diversified learning environment should be created to facilitate the learners and researchers to carry out inquiry learning and cooperative learning activities. The readers' service jobs with multi-levels and multi-patterns should be conducted according to different needs of different readers to improve the utilization rate of paper literature and digital resources.

\subsection{Strengthen the construction of distinctive databases with coordinated development of paper literature and digital resources}

The university library must fully tap the collection resources by using high-tech equipment and technology, and cultivating composite knowledge-based librarians, carefully select library collection materials which can fully reflect the characteristics of the library from Internet free resources such as books, periodicals, newspapers, CD-ROM and OA, and excavate and collate knowledge and information with the same content or subject which are scattered in different carriers and languages through integrating literature information of different carriers to make the information resources turn from dispersion to concentration, from clutter to system, from disorder to order and from uselessness to practicality. On the basis of information collection and literature accumulation, those resources can be processed to make them be standardized information resources such as directory, index, abstract and review, which can also be put together to construct distinctive databases with the characteristics of the library and the resources co-sharing, and bibliography and index for the special topic.

\subsection{Strengthen the construction of discipline collections with coordinated development of paper literature and digital resources}

The discipline collections are mainly reflected in the following aspects. Under the guidance of the collection policy, the funds are scientifically and rationally allocated, and the needs of those key subjects and the backbone disciplines are tracked according to the characteristics of universities' teaching and scientific research. The collections and construction are conducted by means of procurement, exchange and presentation to ensure the systematization and integrity of these disciplines. The discipline collections gradually become the core of the library collection system through accumulation for years or even decades. The libraries in education college should focus on the key disciplines such as higher education, secondary education, primary education, normal education, special education, education management, teacher training and so on in the construction of discipline collection development. Besides, they should reasonably allocate the funds of paper literature and digital resources, conduct scientific analysis via the indicators such as published 
articles quantity, excerpt rate, quotation rate, circulation rate, intelligence density and the amount of information, adopt scientific ways to dynamically determine the core periodicals of key disciplines and scientifically select books and periodicals, selectively buy or rent domestic and foreign educational thematic database, specifically collect online educational open access resources and organically integrate them into paper educational literature to fully reveal their contents, and construct distinctive collections discipline resources and make them electronized to promote the construction of regional literature circulation security system.

\subsection{Strengthen the construction of scientific achievements with coordinated development of paper literature and digital resources}

All the academic works, academic papers, textbooks, teaching reference books, self-made lectures, internship guiding books, syllabuses, teaching plan and research plan which are generated in the process of the establishment of special disciplines and brand professions in universities, some historical materials of the universities, and the academic literatures published by the press in universities have a unique research value, which need the long-time accumulation. The collection, arrangement and storage of those research achievements can form a unique distinctive collection, which is of important reference value to the research in universities. The university library can use the high-tech equipment and technology to digitize the scientific research achievements of the teachers and students according to the key disciplines and specialty of the school and the characteristics of the library, which can effectively promote and strengthen the coordinated development of the paper literature and digital resources.

\section{Summary}

The university library must rationally allocate the paper literature and digital resources, and construct the scientific and rationalized literature resources system. The coordinated development of the paper literature and digital resources can make the university library become the literature information center, academic exchange center, cultural education center and scientific research achievements center in the true sense, which will effectively promote the sustainable development of the university library.

\section{References}

[1] LIANG Fei. Research on library periodical management in universities from the aspect of the utilization ratio of paper periodical [J]. Inner Mongolia science and economy, 2016, (20): 148-149.

[2] Cao Fuyong. Analysis on the service demand of university library in the digital environment [J] .Guangdong Vocational and Technical Education and Research, 2016, (03): 29-32.

[3] CHEN Xueqing, WANG Juanping. Optimal allocation of foreign periodicals in university library based on the sustainable development of document resources [J]. Library Work and Research, 2013, (10): 120-123.

[4] WANG Zhuo. Use and management of the back issues of paper in university library in the digital era [J]. Science and Technology Information Development and Economy, 2013, (05): 36-37.

[5] YOU Zhixian. Research on the coordinated development of paper and digital resources in university library [J]. Lantai World, 2012, (17): 78-79.

[6] LI Zhenhua. Resource allocation of foreign language electronic periodicals in university library in the digital information environment [J]. Library, 2012, (01): 122-124.

[7] CHEN Yuxia. The development and utilization of periodical resources in university library at the digital era [J]. Economist, 2007, (08): $113+115$. 